\title{
Nitrate: A Crucial Signal during Lateral Roots Development
}

\author{
Cui-Hui Sun', Jian-Qiang $\mathrm{Yu}^{2}$ and Da-Gang Hu${ }^{3 *}$ \\ ${ }^{1}$ National Key Laboratory of Crop Biology, Shandong Agricultural University, Tai'An, China, ${ }^{2}$ Ministry of Agriculture Key \\ Laboratory of Horticultural Crop Biology and Germplasm Innovation, Shandong Agricultural University, Tai'An, China, \\ ${ }^{3}$ College of Horticulture Science and Engineering, Shandong Agricultural University, Tai'An, China
}

OPEN ACCESS

Edited by:

Wim Van den Ende,

KU Leuven, Belgium

Reviewed by:

Anis M. Limami,

University of Angers, France

Peng Yu,

University of Bonn, Germany

*Correspondence:

Da-Gang Hu

fap_296566@163.com

Specialty section:

This article was submitted to

Plant Physiology,

a section of the journal

Frontiers in Plant Science

Received: 15 January 2017 Accepted: 20 March 2017

Published: 04 April 2017

Citation:

Sun C-H, Yu J-Q and Hu D-G (2017) Nitrate: A Crucial Signal during Lateral

Roots Development.

Front. Plant Sci. 8:485.

doi: 10.3389/fpls.2017.00485
Root plasticity is an important trait for plants to forage nutrient and adapt to survival in a complicated environment. Lateral roots (LRs) are generally more sensitive than primary roots in response to changing environmental conditions. As the main source of nitrogen for most higher plants, nitrate acting as a signal has received great attention in the regulation of $L R$ development. In general, there are dual effects including stimulatory and inhibitory of low nitrate on LR development; while high nitrate supply has an inhibitory effect on LR development; nitrate heterogeneity also has a stimulatory effect on LR development in $\mathrm{NO}_{3}^{-}$- rich zone. Here, we focus on recent progresses in the role of a nitrate signal in the regulation of the LRs development.

Keywords: nitrate, lateral roots, LR development, primary roots, hormones

\section{INTRODUCTION}

Nitrogen $(\mathrm{N})$ is the most essential macronutrient for plant growth. Plants can absorb various forms of nitrogen, including nitrate $\left(\mathrm{NO}_{3}^{-}\right)$, ammonium $\left(\mathrm{NH}_{4}^{+}\right)$and organic amino acid/peptides from soil. Nitrate is the primary source of nitrogen for most higher plants especially in higher $\mathrm{pH}$ and more aerobic soils (Crawford and Forde, 2002; Masclaux-Daubresse et al., 2010). In addition to its role as nutrient, nitrate has been proved to act as a signal regulating many physiological processes. For instance, it could regulate root systems architecture (RSA), promote floral induction, and relieve seed dormancy in plants (Zhang et al., 1999; Palenchar et al., 2004; Wang et al., 2004; Remans et al., 2006; Marín et al., 2011).

Roots are crucial for perception and uptake of nitrate in plants (Mounier et al., 2014; Léran et al., 2015; Kiba and Krapp, 2016). Lateral root (LR) development contributes considerably to RSA. In general, LRs are more sensitive to variations in nutrient conditions than primary roots (PRs) (Gruber et al., 2013; Tian et al., 2014). Many studies demonstrated that the formation of LR is a post-embryonic event, beginning with the priming of founder cells in the root pericycle. Then a small part of these cells undergoes a series of asymmetrical, anticlinal and periclinal divisions, forming a dome-shaped LR primordium (LRP). After being activated, emerging and elongating, the LRP finally grows into a mature LR (Malamy and Benfey, 1997; Péret et al., 2009; De Smet, 2012; Petricka et al., 2012). In this review, for better understanding, the developmental process of LR is summarized into three stages, including initiation, emergence (formation) and elongation.

There is increasing studies about the effects of nitrate on LR development in higher plants. However, the nitrate signaling pathways regulating LR development are extremely intricate. Different nitrate signaling pathways have different influences on LR development, depending on nitrate concentration and distribution. Here, we review recent advances in understanding the 


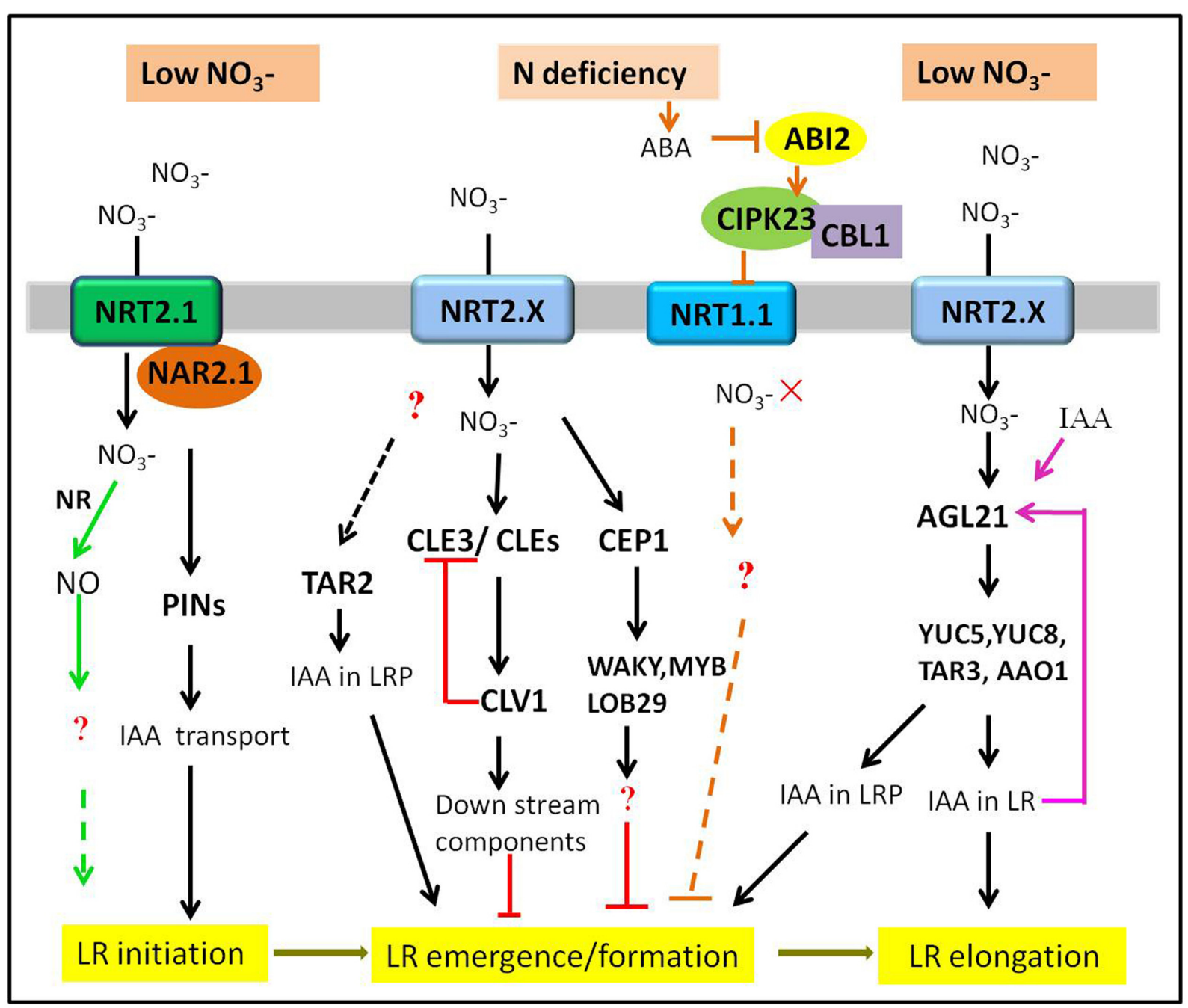

FIGURE 1 | Multiple signaling pathways regulating the LR response to the low $\mathbf{N O}_{3}^{-}$or $\mathbf{N}$ deficiency in plants. Only those pathways discussed in the present review are depicted. The tip of lines with arrows and horizontal lines indicate the positive and negative signaling steps, respectively. NR, nitrate reductase. See text for further explanation.

nitrate signaling pathways that regulate LR development in response to the changes of nitrate supply. The signaling pathways discussed here are illustrated schematically in Figures 1-3.

\section{Dual Roles of Low $\mathrm{NO}_{3}^{-}$on LR Development-Stimulatory and Inhibitory Effects}

Previous studies have demonstrated that plants intend to develop a more exploratory root system with longer LRs under $\mathrm{N}$ deficiency (López-Bucio et al., 2003; Araya et al., 2014a). However, the effect of $\mathrm{N}$ deprivation or low $\mathrm{N}$ on root branching varies depending on the nitrogen nutrition situation of the plant itself and the degree to which the plants are stressed (Forde, 2014). Under mild $\mathrm{N}$ deficiency, the average length of LR was significantly stimulated. However, when subjected to severe $\mathrm{N}$ deficiency, the total length of LR was decreased and LR formation was almost completely absent (Krouk et al., 2010; Gruber et al., 2013). Therefore, it can be predicted that there might be different signaling pathways in the regulation of LR development under $\mathrm{N}$ deficiency conditions in plants.

\section{The Stimulatory Effects of Low Nitrate on LR Development}

Auxin has been proposed as a long-range signal from shoot to root mediating root development in response to nitrate (Forde and Lorenzo, 2001) and there are strong connections between auxin and nitrate signaling, which could cooperatively regulate LR development (Zhang et al., 1999; Gutiérrez et al., 2007; Tian et al., 2008; Krouk et al., 2010; Mounier et al., 2014). A positive effect of mild $\mathrm{N}$ deprivation on $\mathrm{LR}$ formation in Arabidopsis required an auxin biosynthesis gene TAR2 (tryptophan aminotransferase related 2). TAR2 can convert L-Trp to indole-3-pyruvic acid (IPyA), which is the first step in the 


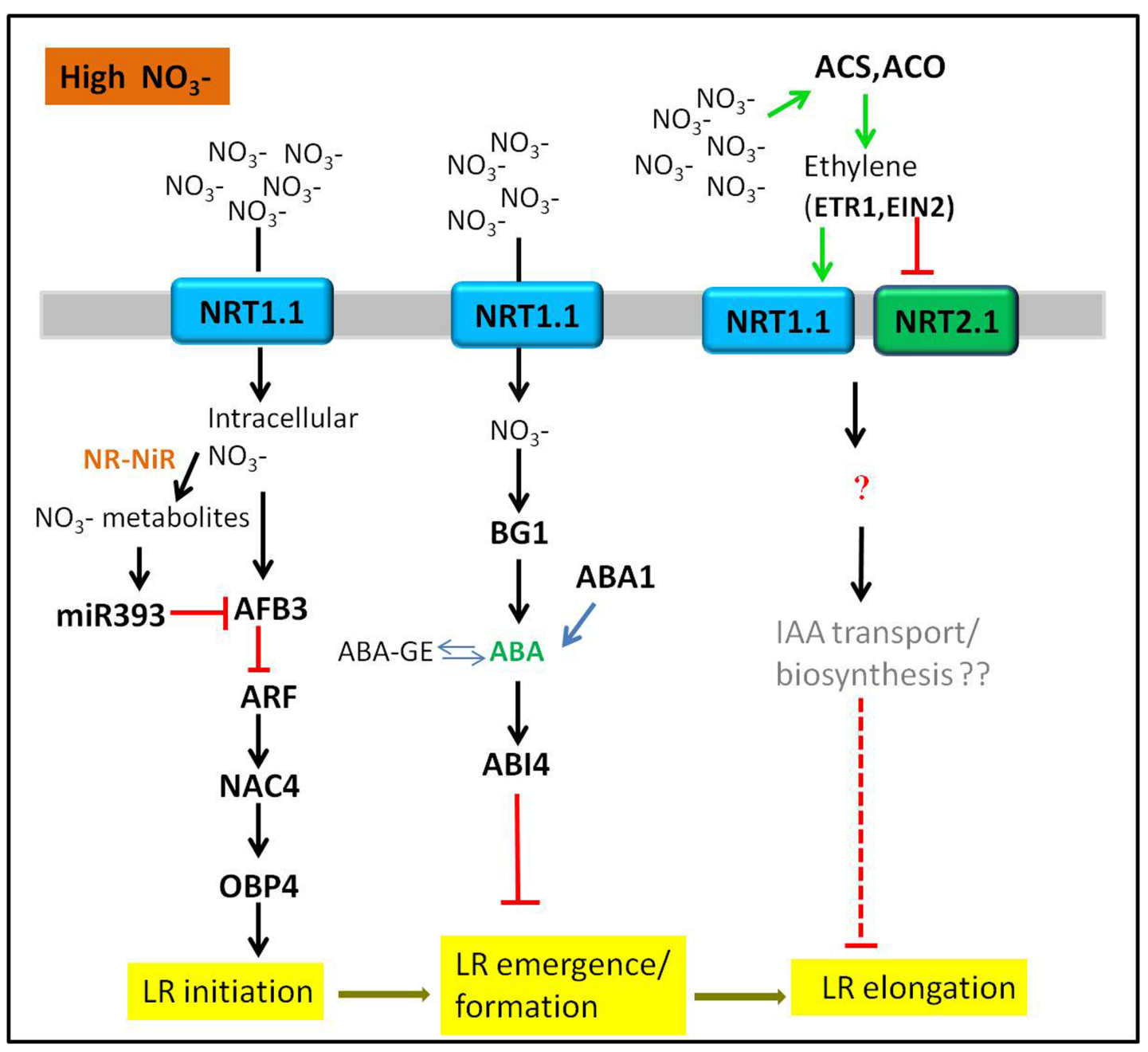

FIGURE 2 | Sensing of high nitrate signals through hormones-mediated LR development. The tip of lines with arrows and horizontal lines indicate the positive and negative signaling steps, respectively. NR, nitrate reductase; NiR, nitrite reductase. See text for further information.

IPyA pathway branching from a Trp-dependent auxin pathway (Tao et al., 2008; Won et al., 2011; Zhao, 2012). Under low $\mathrm{NO}_{3}^{-}$ supply, the expression of TAR2 was up-regulated, resulting in an increase in IAA levels in the developing LRs. However, the tar2-c null mutants had much shorter total LR length and fewer visible LR numbers, indicating that mutation of TAR2 impaired the LR formation (Ma et al., 2014). Therefore, low $\mathrm{NO}_{3}^{-}$-stimulated LR emergence depended on root-synthesized auxin in a TAR2dependent manner. However, the components acting upstream of TAR2 remain unclear.

Another example of the stimulatory effect of low nitrate on LR development was mediated by an Arabidopsis AGL17clade MADs-box gene AGL21. The expression of AGL21 was induced by $\mathrm{N}$ deprivation and auxin. The study found that AGL21-overexpressing plants produced more visible and longer LRs, while agl21 mutants showed a reduction on LR elongation under N-restricted conditions. Moreover, auxin biosynthesis genes YUC5, YUC8, and TAR3 were significantly up-regulated in AGL21-overexpressing plants and down-regulated in agl21 mutants (Yu L. et al., 2014). These findings suggested that AGL21 positively regulated LR development by enhancing local auxin biosynthesis in LR primordia and LRs.

In addition, a previous study on rice revealed that knockdown of OsNAR2.1, the complementary partener of NRT2.1, inhibited LR formation under low $\mathrm{NO}_{3}^{-}$concentrations, by reducing the expression levels of PINs in roots (Huang et al., 2015). This evidence demonstrated that NAR2.1 played a positive role in regulating LRs development by affecting auxin polar transport under low $\mathrm{NO}_{3}^{-}$conditions. As the author mentioned, the effects of NAR2.1 on LR formation were most likely by a combination of $\mathrm{NO}_{3}^{-}$uptake and $\mathrm{NO}_{3}^{-}$signaling. NAR2.1 has no $\mathrm{NO}_{3}^{-}$transport function itself, therefore, the role of NRT2.1 may be indispensable in this signaling pathway, which has not been determined.

Apart from the above-mentioned pathways including transcription factors and hormonal signals, more recently, nitric oxide (NO) has been reported to be a key nitrate-related signal to regulate the root system architecture in plants (Chen et al., 2010; Meng et al., 2012; Trevisan et al., 2014). In rice, NO 


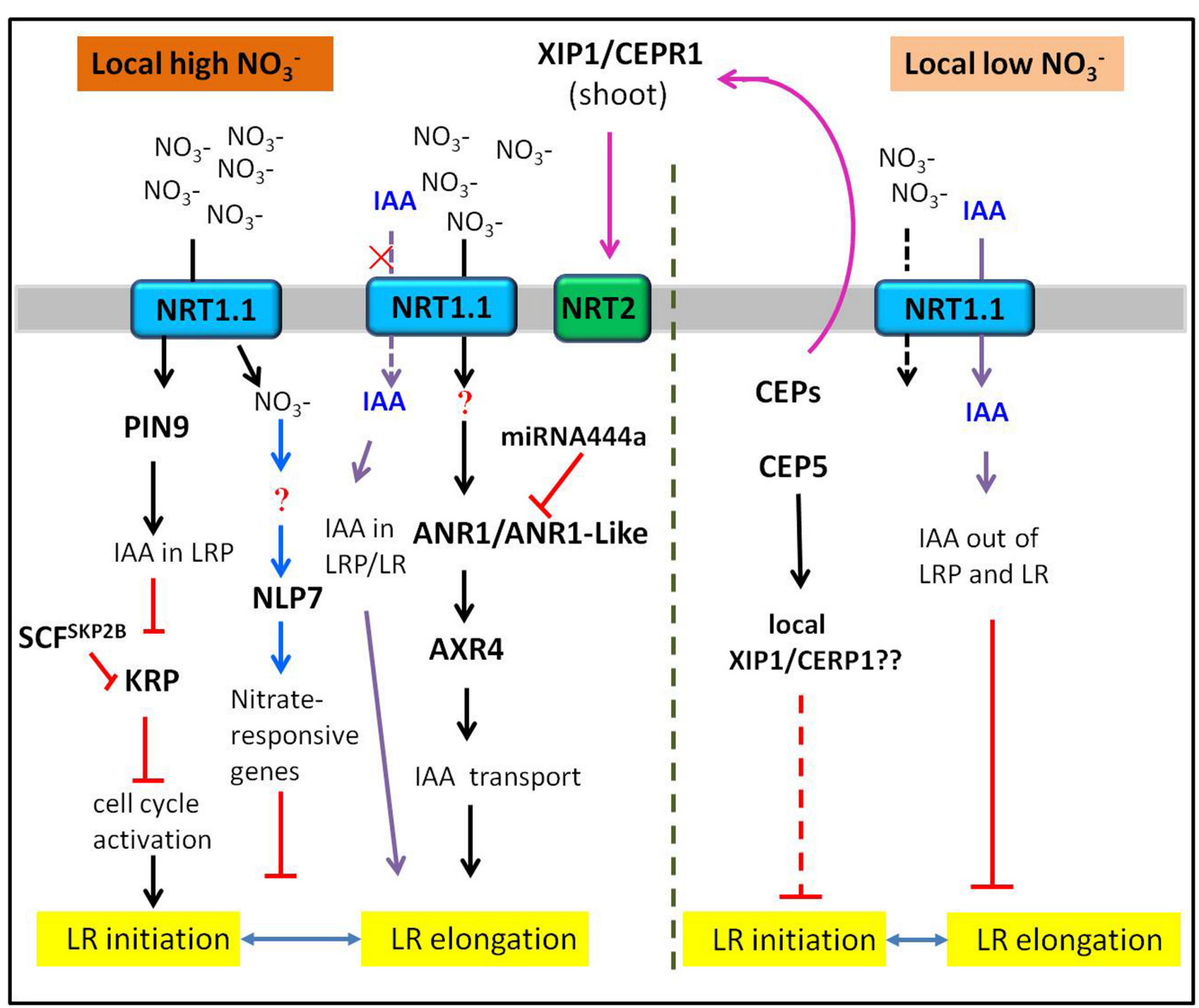

FIGURE 3 | Schematic drawing illustrating the current knowledge on how heterogeneous nitrate influences the LR development. The tip of lines with arrows and horizontal lines indicate the positive and negative signaling steps, respectively. See text for further information.

generated by the nitrate reductase (NR) could improve the $\mathrm{N}$ acquisition capacity by increasing LR initiation under partial nitrate nutrition (Sun et al., 2015). However, a study in maize supported that NO played a key role in early nitrate perception and could induce a more elevated primary root elongation after low nitrate resupply (Manoli et al., 2014). Therefore, the role of $\mathrm{NO}$ in the nitrate signaling pathway needs further evaluation.

In a word, nitrate signaling pathways have a stimulatory effect on LR development under mild $\mathrm{N}$ deficiency. The molecular players involved in the pathways regulate different stages of LR development through affecting not only auxin biosynthesis but its transport. Moreover, we speculate that nitrate signaling components act upstream of auxin on regulating LR development.

\section{The Inhibitory Effect of Severe N Deficiency}

Under severe $\mathrm{N}$ deficiency, both formation and length of LRs were inhibited in plants (Gruber et al., 2013). Further studies indicated that they are involved in CLE [CLV3/ENDOSPERM SURROUNDING REGION (ESR)]-related peptides and the
CLAVATA1 (CLV1) lecuine-rich repeat receptor-like kinase regulatory module. CLEs and its receptors CLVs control meristem functions and were required for maintenance of shoot apical meristem, respectively, in plants (Clark et al., 1997; Brand et al., 2000; Kondo et al., 2006; Mitchum et al., 2008; Ogawa et al., 2008; Stahl et al., 2009). In addition, CLE genes (CLE1, 3,4 and 7) were up-regulated in root pericycle cells when plants were under limited nitrate conditions $(<100 \mu \mathrm{M})$.What's more, the CLE-overexpressing plants had significantly inhibited outgrowth of LRP and their emergence, while the $c l v 1$ mutants exhibited an increased LR growth. Moreover, overexpression of CLE3 inhibited LR growth in wild-type plants, but not in $c l v 1$ mutants. The up-regulation of CLE2, $-3,-4$, and - 7 in $c l v 1$ mutants suggested the amplitude of the CLE peptide was feedbackregulated by CLV1 (Araya et al., 2014a,b). In short, CLEs-CLV acted as a regulatory module in the nitrate signaling pathway and negatively regulated lateral root development under $\mathrm{N}$ deficiency condition. In addition, C-TERMINALLY ENCODED PEPTIDE (CEP) hormones, 15-amino-acid peptides, are proved to be the negative regulators of root development and growth in plants 
(Ohyama et al., 2008; Delay et al., 2013; Tabata et al., 2014). A study in Medicago truncatula found that the expression of $M t C E P 1$ was up-regulated by $\mathrm{N}$ starvation and overexpressing $M t C E P 1$ caused the inhibition on LR formation, indicating that MtCEP1 peptide could negatively modulate LR formation under low $\mathrm{NO}_{3}^{-}$concentrations. The further RNA-seq analysis revealed that transcription factors WRKY, bZIP, MYB and homologs of LOB29, SUPERROOT2, etc., may act downstream of MtCEP1 (Imin et al., 2013).

Another mechanism for systemic inhibition of LR development in response to $\mathrm{N}$ deficiency was identified. Low nitrate triggered a significant increase in ABA accumulation, and ABA accumulation would inactivate its coreceptor ABI2 (ABAinsensitive 2), a protein phosphatase 2C (PP2C) (Joshi-Saha et al., 2011). ABI2 then interacted with and dephosphorylated the $\mathrm{Ca}^{2+}$-sensor subunit CBL1 and the kinase CIPK23 (CBL1CIPK23) complex, whose substrate was NRT1.1. Moreover, CIPK23 could interact with NRT1.1 in the plasma membrane and phosphorylate NRT1.1, which inhibited the activity of NRT1.1 at low nitrate concentrations (Ho et al., 2009). A recent study reconfirmed the above-mentioned speculative pathway. Mutation of ABI2 leads to the activation of CBL1-CIPK23 complex, then results in reduced root $\mathrm{NO}_{3}^{-}$uptake by repressing the transport activity of NRT1.1 under nitrate deficiency (Léran et al., 2015). As ABA could inhibit LR formation by increasing endogenous ABA biosynthesis in plants (Guo et al., 2009) and the downstream components involved in this pathway are still unclear. Therefore, it is ambiguous whether the negative influence on LR development involving ABA under $\mathrm{N}$ deficiency is due to the impaired $\mathrm{NO}_{3}^{-}$signaling effects or ABA physiological function.

In addition, there are some evidences that nitrate transporters with a sensing role are involved in nitrate signaling pathway. NRT1.1 acts as $\mathrm{NO}_{3}^{-}$transceptor, with a dual transporter/sensor function in signaling pathway (Remans et al., 2006; Ho et al., 2009; Gojon et al., 2011). However, NRT1.1 could control the growth of LRP under the absence of $\mathrm{NO}_{3}^{-}$or low $\mathrm{NO}_{3}^{-}$condition (Bouguyon et al., 2016). While under N-limited condition, AtNRT2.1 might act as $\mathrm{NO}_{3}^{-}$sensor or signaling component repressing LR initiation, which was independent of its $\mathrm{NO}_{3}^{-}$ uptake activity (Little et al., 2005; Remans et al., 2006). Finally, although the definite mechanism is still uncertain, the negative effect of NRT1.1/NRT2.1 on LR development may represent a distinct systemic pathway under low nitrate conditions.

In all, although acting antagonistically and having opposite effects, these systemic pathways coexist to regulate LR development in response to low $\mathrm{N}$. Which pathway taking action depends on the degree of $\mathrm{N}$ deficiency that the plants suffered from or their specific environment conditions.

\section{The Inhibitory Effect of High Nitrate Supply on LR Development}

Compared with low nitrate supply, uniform supply of nitrate higher than $10 \mathrm{mM}$ could systematically inhibit both LR branching and LR average length mainly through hormones signaling pathways (Zhang et al., 1999; Tian et al., 2009). There are several possible explanations for the inhibitory effect of high nitrate on LR development.

\section{Auxin and Auxin Signaling}

Auxin biosynthesis, polar transport, and signal transduction are key players in regulation of LR development (Casimiro et al., 2001; De Smet et al., 2006; Laskowski et al., 2008; Rubio et al., 2009; Krouk et al., 2011; De Smet, 2012). Therefore, the involvement of auxin in the high nitrate concentration-induced inhibitory effect on LR development is of no surprise. Auxin receptor $A F B 3$ was strongly induced by high nitrate concentration, but was significantly repressed by $\mathrm{NO}_{3}^{-}$metabolites via the feedback regulation by miR393 (Vidal et al., 2010). miR393/AFB3 was identified as a unique module to regulate LR initiation in Arabidopsis. The pathway was extended by the founding that nitrate-induction of transcription factors NAC4 and OBP4 required the existence of AFB3; Similar to the afb3 mutant, a nac4 mutant was less sensitive to nitratestimulated LR initiation. Meanwhile, the expression of OBP4 was significantly reduced in nac4 mutants (Vidal et al., 2013). Therefore, it can be speculated that AFB3 acts upstream of NAC4 and $O B P 4$ to regulate the density of LR. A recent study has extended this pathway in the other direction, nitrate-regulation of $A F B 3$ and NAC4 is dependent on the $\mathrm{NO}_{3}^{-}$transport function of NRT1.1, but not its sensing function (Vidal et al., 2014). Except for an auxin signaling pathway, high nitrate regulates LR development also through affecting auxin levels in roots. For instance, when external nitrate concentration was greater than $10 \mathrm{mM}$, the elongation of LRs in maize was inhibited, which was due to a reduction of auxin translocation from shoot to root in phloem. Therefore, a reduced auxin level in roots resulted in the inhibition of LR growth (Tian et al., 2008).

\section{$A B A$ and $A B A$ Signaling}

At high concentrations, nitrate inhibited LR outgrowth through ABA signaling (Signora et al., 2001; Vidal et al., 2010). ABA insensitive mutants abi4-1, abi4-2 and abi5-1 were less sensitive to the inhibitory effect of high nitrate on LR; and ABA synthesis mutant abas produced a significant increase in LR growth, suggesting that the inhibitory effect caused by high nitrate on LR growth was required for both $\mathrm{ABA}$ accumulation and signaling (Signora et al., 2001). In addition, genetic analysis revealed that ABA signaling acted downstream of $\mathrm{NO}_{3}^{-}$perception in the regulation of root architecture (Signora et al., 2001). However, a new study demonstrates that high $\mathrm{NO}_{3}^{-}$supply $(30 \mathrm{mM})$ stimulates $\mathrm{ABA}$ accumulation in growing roots tips by releasing it from inactive stores via ER-localized $\beta$-GLUCOSIDASE1 (BG1), thereby regulating root growth (Ondzighi-Assoume et al., 2016). These data provide a mechanism for $\mathrm{NO}_{3}^{-}$-regulated root growth via the regulation of $\mathrm{ABA}$ accumulation in the root tip. In conclusion, we can speculate that there is a close interaction between $\mathrm{ABA}$ and nitrate signaling, which could jointly regulate LR formation.

\section{Ethylene Production and Signaling}

Many evidences proved that ethylene inhibited LR development in plants by altering auxin transport and there was crosstalk 
between ethylene and auxin in regulating LR formation (Ivanchenko et al., 2008; Negi et al., 2008; Lewis et al., 2011). However, the crosstalk between ethylene and nitrate signaling regulating LR development is rarely reported. A previous study found that ethylene was involved in nitrate-dependent LR growth and branching in Arabidopsis. High nitrate induced a rapid burst of ethylene in immature LRs. The ethylene burst then upregulated and downregulated the expression of AtNRT1.1 and AtNRT2.1 in roots, respectively, resulting in the inhibition of immature LR growth in Arabidopsis. In addition, the etr1-3 and ein2-1 mutants were insensitive to high nitrate concentrations, suggesting that ethylene signaling genes ETR1 and EIN2 might involve in this regulatory pathway (Tian et al., 2009). As there is no related study exploring the players downstream of NRT1.1 and NRT2.1, the mechanism of LR inhibition by ethylene under high nitrate condition becomes obscure. However, IAA and ACC (the precursor of ethylene) could inhibit root elongation synergistically (Stepanova et al., 2007; Swarup et al., 2007). The auxin transport or biosynthesis mediated by ethylene may be the possible explanation under this situation.

\section{The Stimulatory Effect of $\mathrm{NO}_{3}^{-}$ Heterogeneity on LR Development}

In response to $\mathrm{NO}_{3}^{-}$heterogeneity (uneven $\mathrm{NO}_{3}^{-}$distribution), most plants could direct preferential LR growth into a $\mathrm{NO}_{3}^{-}$ rich zone (Zhang et al., 1999; Giehl et al., 2012). In Arabidopsis, local high supply of nitrate specifically stimulated LR elongation (Zhang et al., 1999), while in adult maize, both the length and density of LRs from shoot-borne roots were increased in response to local high nitrate (Yu P. et al., 2014; Yu et al., 2015). The same case was also reported much earlier in barley that the localized nitrate supply could cause an increase in both the numbers and growth rate of LRs (Drew and Saker, 1975). Moreover, the density of LRs on seminal root of rice was increased in response to local $\mathrm{NO}_{3}^{-}$supply (Huang et al., 2015). Many researches have proved that $\mathrm{NO}_{3}^{-}$acted as a signal rather than nutrient to regulate LR proliferation in a localized $\mathrm{NO}_{3}^{-}$rich patch (Zhang et al., 1999; Remans et al., 2006; Krouk et al., 2010). Meanwhile, much progresses have been made to explore the molecular mechanism of stimulatory effect on LR development caused by $\mathrm{NO}_{3}^{-}$heterogeneity.

The first molecular player identified in the signaling pathway is ANR1, which belongs to the MADS-box transcription factor family. ANR1 was proved as a positive regulator in the signaling pathway of local nitrate-stimulated LR proliferation (Zhang and Forde, 1998; Gan et al., 2012). However, the realization of full function of ANR1 requires the presence of nitrate, indicating that there may be other components in this signaling pathway. Later study found that NRT1.1 functioned upstream of ANR1 in regulating LR elongation, apparently by its role as a $\mathrm{NO}_{3}^{-}$ sensor (Remans et al., 2006). The auxin-resistant mutant axr4 shows no increase in LR elongation after exposure to localized nitrate supply (Zhang et al., 1999), suggesting that AXR4 gene might be essential for the stimulatory effect of local $\mathrm{NO}_{3}^{-}$ signaling. To further explore the members involved in this signaling pathway, we found a recent study on a monocotsspecific miRNA, which could target ANR1 homologous genes and affect LR elongation. MiR444a-overexpressing rice lowered the expression of ANR1-like genes (OsMADS-23, OsMADS$27 a$ and OsMADS-57) and impaired the stimulatory effects of localized $\mathrm{NO}_{3}^{-}$on LR growth (Yan et al., 2014). These results indicate that miR444a may participate in the local $\mathrm{NO}_{3}^{-}$-signaling pathway by mediating the expression of ANR1homologous genes. Except for $\mathrm{NO}_{3}^{-}$transport activity, NRT1.1 also basipetally transports auxin, which is $\mathrm{NO}_{3}^{-}$-dependent (Krouk et al., 2010). Local low nitrate supply facilitates NRT1.1mediated auxin flux, thus depleting auxin levels in LRP and inhibiting its outgrowth. Conversely, local high nitrate could promote LR development as a result of auxin accumulation in LR primordia and tips by suppressing the NRT1.1-auxin transport activity (Mounier et al., 2014). The role of NRT1.1 repressing LR development on the local low nitrate part in the split root system was similar to its previously identified negative effect under $\mathrm{N}$ deficiency. The mechanism discussed here involving in auxin basipetal transport by NRT1.1 may also explain the negative effect by NRT1.1 in the uniform low $\mathrm{NO}_{3}^{-}$ condition.

Apart from the NRT1.1-ANR1 involved nitrate signaling pathway, various kinds of new molecular players have been identified guiding different signaling pathway under heterogeneous nitrate conditions. Recent studies on root development in adult maize have been attractive. In adult maize, local high nitrate induces LR initiation in shoot-borne roots of maize by PIN9-mediated auxin efflux and by auxin/SCF ${ }^{\text {SKP2B }}$ mediated repression of Kip-related proteins (KRPs), giving rise to subsequent cell-cycle activation in LRP under heterogeneous nitrate conditions (Yu P. et al., 2014; Yu et al., 2015). In addition, the cell type specific RNA-seq experiments revealed that the pericycle cells of brace roots displayed unique transcriptomic reprogramming upon heterogeneous nitrate supply, indicating a specific LR branching pattern on brace roots ( $\mathrm{Yu}$ et al., 2016).

Besides, CEPs and its membrane-bound receptors are able to control LR growth and development as well in plants (Imin et al., 2013; Roberts et al., 2013; Mohd-Radzman et al., 2016). The low N-produced CEPs act as a long-distance signal through shoot-located XYLEM INTERMIXED WITH PHLOEM 1 (XIP1)/CEP RECEPTOR 1(CEPR1) to up-regulate high-affinity nitrate transporter genes in roots under local high N (Tabata et al., 2014). Further study reveals that auxin-repressive CEP5 inhibits LR initiation probably depending on XIP1/CEPR1 under local high N (Roberts et al., 2016). However, due to restrictions of the extract technique, adaptable methods and approaches on CEPs as well as a lack of a XIP1/CEPR1 knockout mutant, it is much more difficult to gain a complete understanding of CEP signal regulating LR development.

An important advance in the nitrate signaling pathway has been verified. For example, NLPs are a key regulator of nitratedependent physiological processes in higher plants (Konishi and Yanagisawa, 2013). One member, NLP7, is not nitrate-responsive at the transcriptional level, but mediates early nitrate sensing and assimilation (Castaings et al., 2009). Further study unraveled 
that NLP7 played a key role in LR development in response to nitrate. These studies found that the nlp7 mutants have an increased LR density on the high $\mathrm{NO}_{3}^{-}$side, and are impaired in nitrate sensing and nitrate assimilation. In addition, $n l p 7$ mutants show severe inhibition of LR growth on both high- and lownitrate media on split-root plates, indicating NLP7 may mediate local nitrate responses (Marchive et al., 2013; Guan et al., 2014). However, the existing studies indirectly put forward the potential role of NLP7 in regulating LR development under different nitrate availability. It seems that NLP7 has a negative effect on LR development, which still requires further investigation.

\section{CONCLUSION AND PERSPECTIVES}

There have been rapid advances in understanding the molecular mechanism that regulate LR growth and development under different $\mathrm{NO}_{3}^{-}$conditions in different higher plants. The signaling pathways discussed here show us the complexity of nitrate regulation of LR development. Not only the redundancy but sometimes even antagonism between different pathways is confusing in understanding, let alone much more unexplored components in some pathways. Fortunately, systems biology approaches including the emergence of new genome-editing technologies such as CRISP-Cas9, as well as the highthroughout RNA sequencing technologies allow for identification of candidate genes, which will lead to significant advances in the future.

Most of the studies cited in this review are mainly focusing on model plants. By comparing, the cereal crops such as maize and rice have more complex root systems than the model plant Arabidopsis. What's more, except the common pathway controlling LR initiation, there are unique root-typespecific pathways in cereal crops, which primarily regulate LR formation. For example, despite the evolutionary differences between Arabidopsis and rice, the function of ANR1/ANR1-like genes in nitrate regulation of LR growth is highly conserved. So the knowledge of nitrate signaling pathways gained from Arabidopsis would be applicable to cereal crops. However, the above-mentioned gene PIN9 is monocot-root specific, which is

\section{REFERENCES}

Araya, T., Miyamoto, M., Wibowo, J., Suzuki, A., Kojima, S., Tsuchiya, Y. N., et al. (2014a). CLE-CLAVATA1 peptide-receptor signaling module regulates the expansion of plant root systems in a nitrogen-dependent manner. Proc. Natl. Acad. Sci. U.S.A. 111, 2029-2034. doi: 10.1073/pnas.131995 3111

Araya, T., von Wirén, N., and Takahashi, H. (2014b). CLE peptides regulate lateral root development in response to nitrogen nutritional status of plants. Plant Signal. Behav. 9, 2029-2034. doi: 10.4161/psb.29302

Bouguyon, E., Perrine-Walker, F., Pervent, M., Rochette, J., Cuesta, C., Benkova, E., et al. (2016). Nitrate controls root development through posttranscriptional regulation of the NRT1.1/NPF6.3 transporter/sensor. Plant Physiol. 172, 1237-1248. doi: 10.1104/pp.16.01047

Brand, U., Fletcher, J. C., Hobe, M., Meyerowitz, E. M., and Simon, R. (2000). Dependence of stem cell fate in Arabidopsis on a feedback loop regulated by CLV3 activity. Science 289, 617-619. doi: 10.1126/science.289. 5479.617 highly expressed in LPRs in maize, controlling auxin transport and redistribution triggered by local nitrate supply. Therefore, it is noteworthy that the molecular mechanisms regulating LR development in response to nitrate in Arabidopsis and cereal crops sometimes are in common use, however, sometimes may be species-specific.

Plants absorb various types of nitrogen from the soil, however, only nitrate possesses such unique and vital signaling effects on LR development. What's more, the signaling effect of nitrate is partly far more important than its nutrimental function. Many evidences suggest that nitrate signaling effects exert indispensable physiological meaning for plant growth and adaptation to changing survival environment. For example, under nitratelimited conditions (low $\mathrm{NO}_{3}^{-}$supply), plants tend to adapt a 'foraging strategy' with LR proliferation for more nutrients. By contrast, in nitrate-repleted conditions (high $\mathrm{NO}_{3}^{-}$supply), plant roots adapt an economic saving model with LR inhibition to reserve energy for other usage. However, uneven nitrate distribution in the soil could trigger more LRs foraging more nutrients in $\mathrm{NO}_{3}^{-}$-rich zones in order to compensate for the limited $\mathrm{N}$ acquisition in $\mathrm{NO}_{3}^{-}$-deficient patches. On thinking of this, we couldn't help admiring plants for their strong adaptability to the environment.

\section{AUTHOR CONTRIBUTIONS}

C-HS, D-GH, J-QY wrote the manuscript. D-GH provided assistance for further modification of manuscript. All authors listed, have made substantial, direct and intellectual contribution to the work, and approved it for publication.

\section{ACKNOWLEDGMENTS}

This work was supported by grants from NSFC (31601728), Shandong Province (ZR2016CQ13) and Youth Science and Technology Innovation Fund of Shandong Agricultural University (24024).

Casimiro, I., Marchant, A., Bhalerao, R. P., Beeckman, T., Dhooge, S., Swarup, R., et al. (2001). Auxin transport promotes Arabidopsis lateral root initiation. Plant Cell 13, 843-852. doi: 10.1105/tpc.13.4.843

Castaings, L., Camargo, A., Pocholle, D., Gaudon, V., Texier, Y., Boutet-Mercey, S., et al. (2009). The nodule inception-like protein 7 modulates nitrate sensing and metabolism in Arabidopsis. Plant J. 57, 426-435. doi: 10.1111/j.1365-313X. 2008.03695.x

Chen, W. W., Yang, J. L., Qin, C., Jin, C. W., Mo, J. H., Ye, T., et al. (2010). Nitric oxide acts downstream of auxin to trigger root ferric-chelate reductase activity in response to iron deficiency in Arabidopsis. Plant Physiol. 154, 810-819. doi: $10.1104 /$ pp.110.161109

Clark, S. E., Williams, R. W., and Meyerowitz, E. M. (1997). The CLAVATA1 gene encodes a putative receptor kinase that controls shoot and floral meristem size in Arabidopsis. Cell 89, 575-585. doi: 10.1016/S0092-8674(00)80239-1

Crawford, N. M., and Forde, B. G. (2002). Molecular and developmental biology of inorganic nitrogen nutrition. Arabidopsis Book 1:e0011. doi: 10.1199/tab.0011

De Smet, I. (2012). Lateral root initiation: one step at a time. New Phytol. 193, 867-873. doi: 10.1111/j.1469-8137.2011.03996.x 
De Smet, I., Vanneste, S., Inzé, D., and Beeckman, T. (2006). Lateral root initiation or the birth of a new meristem. Plant Mol. Biol. 60, 871-887. doi: 10.1007/ s11103-005-4547-2

Delay, C., Imin, N., and Djordjevic, M. A. (2013). CEP genes regulate root and shoot development in response to environmental cues and are specific to seed plants. J. Exp. Bot. 64, 5383-5394. doi: 10.1093/jxb/ert332

Drew, M. C., and Saker, L. R. (1975). Nutrient supply and the growth of the seminal root system in Barley II. Localized, compensatory increases in lateral root growth and rates op nitrate uptake when nitrate supply is restricted to only part of the root system. J. Exp. Bot. 26, 79-90. doi: 10.1093/jxb/ 26.1.79

Forde, B., and Lorenzo, H. (2001). The nutritional control of root development. Plant Soil 232, 51-68. doi: 10.1023/A:1010329902165

Forde, B. G. (2014). Nitrogen signaling pathways shaping root system architecture: an update. Curr. Opin. Plant Biol. 21, 30-36. doi: 10.1016/j.pbi.2014. 06.004

Gan, Y., Bernreiter, A., Filleur, S., Abram, B., and Forde, B. G. (2012). Overexpressing the ANR1 MADS-box gene in transgenic plants provides new insights into its role in the nitrate regulation of root development. Plant Cell Physiol. 53, 1003-1016. doi: 10.1093/pcp/pcs050

Giehl, R. F., Lima, J. E., and von Wirén, N. (2012). Localized iron supply triggers lateral root elongation in Arabidopsis by altering the AUX1-mediated auxin distribution. Plant Cell 24, 33-49. doi: 10.1105/tpc.111.092973

Gojon, A., Krouk, G., Perrine-Walker, F., and Laugier, E. (2011). Nitrate transceptor (s) in plants. J. Exp. Bot. 62, 2299-2308. doi: 10.1093/jxb/erq419

Gruber, B. D., Giehl, R. F., Friedel, S., and von Wirén, N. (2013). Plasticity of the Arabidopsis root system under nutrient deficiencies. Plant Physiol. 163, 161-179. doi: 10.1104/pp.113.218453

Guan, P., Wang, R., Nacry, P., Breton, G., Kay, S. A., Pruneda-Paz, J. L., et al. (2014). Nitrate foraging by Arabidopsis roots is mediated by the transcription factor TCP20 through the systemic signaling pathway. Proc. Natl. Acad. Sci. U.S.A. 111, 15267-15272. doi: 10.1073/pnas.1411375111

Guo, D., Liang, J., and Li, L. (2009). Abscisic acid (ABA) inhibition of lateral root formation involves endogenous ABA biosynthesis in Arachis hypogaea L. Plant Growth Regul. 58, 173-179. doi: 10.1007/s10725-009-9365-0

Gutiérrez, R. A., Lejay, L. V., Dean, A., Chiaromonte, F., Shasha, D. E., and Coruzzi, G. M. (2007). Qualitative network models and genome-wide expression data define carbon/nitrogen-responsive molecular machines in Arabidopsis. Genome Boil. 8:R7. doi: 10.1186/gb-2007-8-1-r7

Ho, C. H., Lin, S. H., Hu, H. C., and Tsay, Y. F. (2009). CHL1 functions as a nitrate sensor in plants. Cell 138, 1184-1194. doi: 10.1016/j.cell.2009.07.004

Huang, S., Chen, S., Liang, Z., Zhang, C., Yan, M., Chen, J., et al. (2015). Knockdown of the partner protein OsNAR2.1 for high-affinity nitrate transport represses lateral root formation in a nitrate-dependent manner. Sci. Rep. 8:18192. doi: $10.1038 /$ srep 18192

Imin, N., Mohd-Radzman, N. A., Ogilvie, H. A., and Djordjevic, M. A. (2013). The peptide-encoding CEP1 gene modulates lateral root and nodule numbers in Medicago truncatula. J. Exp. Bot. 64, 5395-5409. doi: 10.1093/jxb/ ert369

Ivanchenko, M. G., Muday, G. K., and Dubrovsky, J. G. (2008). Ethylene-auxin interactions regulate lateral root initiation and emergence in Arabidopsis thaliana. Plant J. 55, 335-347. doi: 10.1111/j.1365-313X.2008.03528.x

Joshi-Saha, A., Valon, C., and Leung, J. (2011). A brand new START: abscisic acid perception and transduction in the guard cell. Sci. Signal. 4, re4. doi: 10.1126/ scisignal.2002164

Kiba, T., and Krapp, A. (2016). Plant nitrogen acquisition under low availability: regulation of uptake and root architecture. Plant Cell Physiol. 57, 707-714. doi: $10.1093 / \mathrm{pcp} / \mathrm{pcw} 052$

Kondo, T., Sawa, S., Kinoshita, A., Mizuno, S., Kakimoto, T., Fukuda, H., et al. (2006). A plant peptide encoded by CLV3 identified by in situ MALDI-TOF MS analysis. Science 313, 845-848. doi: 10.1126/science.1128439

Konishi, M., and Yanagisawa, S. (2013). Arabidopsis NIN-like transcription factors have a central role in nitrate signaling. Nat. Commun. 4:1617. doi: 10.1038/ ncomms 2621

Krouk, G., Lacombe, B., Bielach, A., Perrine-Walker, F., Malinska, K., Mounier, E., et al. (2010). Nitrate-regulated auxin transport by NRT1. 1 defines a mechanism for nutrient sensing in plants. Dev. Cell 18, 927-937. doi: 10.1016/j.devcel.2010. 05.008
Krouk, G., Ruffel, S., Gutiérrez, R. A., Gojon, A., Crawford, N. M., Coruzzi, G. M., et al. (2011). A framework integrating plant growth with hormones and nutrients. Trends Plant Sci. 16, 178-182. doi: 10.1016/j.tplants.2011.02.004

Laskowski, M., Grieneisen, V. A., Hofhuis, H., Colette, A., Hogeweg, P., Marée, A. F., et al. (2008). Root system architecture from coupling cell shape to auxin transport. PLoS Biol. 6:e307. doi: 10.1371/journal.pbio.0060307

Léran, S., Edel, K. H., Pervent, M., Hashimoto, K., Corratgé-Faillie, C., Offenborn, J. N., et al. (2015). Nitrate sensing and uptake in Arabidopsis are enhanced by ABI2, a phosphatase inactivated by the stress hormone abscisic acid. Sci. Signal. 8, ra43. doi: 10.1126/scisignal.aaa4829

Lewis, D. R., Negi, S., Sukumar, P., and Muday, G. K. (2011). Ethylene inhibits lateral root development, increases IAA transport and expression of PIN3 and PIN7 auxin efflux carriers. Development 138, 3485-3495. doi: 10.1242/dev. 065102

Little, D. Y., Rao, H., Oliva, S., Daniel-Vedele, F., Krapp, A., and Malamy, J. E. (2005). The putative high-affinity nitrate transporter NRT2. 1 represses lateral root initiation in response to nutritional cues. Proc. Natl. Acad. Sci. U.S.A. 102, 13693-13698. doi: 10.1073/pnas.0504219102

López-Bucio, J., Cruz-Ramı ìrez, A., and Herrera-Estrella, L. (2003). The role of nutrient availability in regulating root architecture. Curr. Opin. Plant Biol. 6, 280-287. doi: 10.1016/S1369-5266(03)00035-9

Ma, W., Li, J., Qu, B., He, X., Zhao, X., Li, B., et al. (2014). Auxin biosynthetic gene TAR2 is involved in low nitrogen-mediated reprogramming of root architecture in Arabidopsis. Plant J. 78, 70-79. doi: 10.1111/tpj.12448

Malamy, J. E., and Benfey, P. N. (1997). Organization and cell differentiation in lateral roots of Arabidopsis thaliana. Development 124, 33-44. doi: 10.1007/ 9006065-010

Manoli, A., Begheldo, M., Genre, A., Lanfranco, L., Trevisan, S., and Quaggiotti, S. (2014). NO homeostasis is a key regulator of early nitrate perception and root elongation in maize. J. Exp. Bot. 65, 185-200. doi: 10.1093/jxb/ert358

Marchive, C., Roudier, F., Castaings, L., Brehaut, V., Blondet, E., Colot, V., et al. (2013). Nuclear retention of the transcription factor NLP7 orchestrates the early response to nitrate in plants. Nat. Commun. 4:1713. doi: 10.1038/ncomms 2650

Marín, I. C., Loef, I., Bartetzko, L., Searle, I., Coupland, G., Stitt, M., et al. (2011). Nitrate regulates floral induction in Arabidopsis, acting independently of light, gibberellin and autonomous pathways. Planta 233, 539-552. doi: 10.1007/ s00425-010-1316-5

Masclaux-Daubresse, C., Daniel-Vedele, F., Dechorgnat, J., Chardon, F., Gaufichon, L., and Suzuki, A. (2010). Nitrogen uptake, assimilation and remobilization in plants: challenges for sustainable and productive agriculture. Ann. Bot. 105, 1141-1157. doi: 10.1093/aob/mcq028

Meng, Z. B., Chen, L. Q., Suo, D., Li, G. X., Tang, C. X., and Zheng, S. J. (2012). Nitric oxide is the shared signaling molecule in phosphorus-and irondeficiency-induced formation of cluster roots in white lupin (Lupinus albus). Ann. Bot. 109, 1055-1064. doi: 10.1093/aob/mcs024

Mitchum, M. G., Wang, X., and Davis, E. L. (2008). Diverse and conserved roles of CLE peptides. Curr. Opin. Plant Boil. 11, 75-81. doi: 10.1016/j.pbi.2007.10.010

Mohd-Radzman, N. A., Laffont, C., Ivanovici, A., Patel, N., Reid, D. E., Stougaard, J., et al. (2016). Different pathways act downstream of the peptide receptor CRA2 to regulate lateral root and nodule development. Plant Physiol. 171, 2536-2548. doi: 10.1104/pp.16.00113

Mounier, E., Pervent, M., Ljung, K., Gojon, A., and Nacry, P. (2014). Auxinmediated nitrate signaling by NRT1. 1 participates in the adaptive response of Arabidopsis root architecture to the spatial heterogeneity of nitrate availability. Plant Cell Environ. 37, 162-174. doi: 10.1111/pce.12143

Negi, S., Ivanchenko, M. G., and Muday, G. K. (2008). Ethylene regulates lateral root formation and auxin transport in Arabidopsis thaliana. Plant J. 55, 175-187. doi: 10.1111/j.1365-313X.2008.03495.x

Ogawa, M., Shinohara, H., Sakagami, Y., and Matsubayashi, Y. (2008). Arabidopsis CLV3 peptide directly binds CLV1 ectodomain. Science 319, 294-294. doi: $10.1126 /$ science. 1150083

Ohyama, K., Ogawa, M., and Matsubayashi, Y. (2008). Identification of a biologically active, small, secreted peptide in Arabidopsis by in silico gene screening, followed by LC-MS-based structure analysis. Plant J. 55, 152-160. doi: 10.1111/j.1365-313X.2008.03464.x

Ondzighi-Assoume, C. A., Chakraborty, S., and Harris, J. M. (2016). Environmental nitrate stimulates abscisic acid accumulation in Arabidopsis 
root tips by releasing it from inactive stores. Plant Cell 28, 729-745. doi: 10.1105/tpc.15.00946

Palenchar, P. M., Kouranov, A., Lejay, L. V., and Coruzzi, G. M. (2004). Genomewide patterns of carbon and nitrogen regulation of gene expression validate the combined carbon and nitrogen $(\mathrm{CN})$-signaling hypothesis in plants. Genome Biol. 5:R91. doi: 10.1186/gb-2004-5-11-r91

Péret, B., De Rybel, B., Casimiro, I., Benková, E., Swarup, R., Laplaze, L., et al. (2009). Arabidopsis lateral root development: an emerging story. Trends Plant Sci. 14, 399-408. doi: 10.1016/j.tplants.2009.05.002

Petricka, J. J., Winter, C. M., and Benfey, P. N. (2012). Control of Arabidopsis root development. Ann. Rev. Plant Biol. 63, 563-590. doi: 10.1146/annurev-arplant042811-105501

Remans, T., Nacry, P., Pervent, M., Filleur, S., Diatloff, E., Mounier, E., et al. (2006). The Arabidopsis NRT1. 1 transporter participates in the signaling pathway triggering root colonization of nitrate-rich patches. Proc. Natl. Acad. Sci. U.S.A. 103, 19206-19211. doi: 10.1073/pnas.0605275103

Roberts, I., Smith, S., De Rybel, B., Van Den Broeke, J., Smet, W., De Cokere, S., et al. (2013). The CEP family in land plants: evolutionary analyses, expression studies, and a role in Arabidopsis shoot development. J. Exp. Bot. 64, 5371-5381. doi: $10.1093 /$ jxb/ert331

Roberts, I., Smith, S., Stes, E., De Rybel, B., Staes, A., Van De Cotte, B., et al. (2016). CEP5 and XIP1/CEPR1 regulate lateral root initiation in Arabidopsis. J. Exp. Bot. 67, 4889-4899. doi: 10.1093/jxb/erw231

Rubio, V., Bustos, R., Irigoyen, M. L., Cardona-López, X., Rojas-Triana, M., and Paz-Ares, J. (2009). Plant hormones and nutrient signaling. Plant Mol. Biol. 69, 361-373. doi: 10.1007/s11103-008-9380-y

Signora, L., De Smet, I., Foyer, C. H., and Zhang, H. (2001). ABA plays a central role in mediating the regulatory effects of nitrate on root branching in Arabidopsis. Plant J. 28, 655-662. doi: 10.1046/j.1365-313x.2001. 01185.x

Stahl, Y., Wink, R. H., Ingram, G. C., and Simon, R. (2009). A signaling module controlling the stem cell niche in Arabidopsis root meristems. Curr. Biol. 19, 909-914. doi: 10.1016/j.cub.2009.03.060

Stepanova, A. N., Yun, J., Likhacheva, A. V., and Alonso, J. M. (2007). Multilevel interactions between ethylene and auxin in Arabidopsis roots. Plant Cell 19, 2169-2185. doi: 10.1105/tpc.107.052068

Sun, H., Li, J., Song, W., Tao, J., Huang, S., Chen, S., et al. (2015). Nitric oxide generated by nitrate reductase increases nitrogen uptake capacity by inducing lateral root formation and inorganic nitrogen uptake under partial nitrate nutrition in rice. J. Exp. Bot. 66, 2449-2459. doi: 10.1093/jxb/ erv030

Swarup, R., Perry, P., Hagenbeek, D., Van Der Straeten, D., Beemster, G. T., Sandberg, G., et al. (2007). Ethylene upregulates auxin biosynthesis in Arabidopsis seedlings to enhance inhibition of root cell elongation. Plant Cell 19, 2186-2196. doi: 10.1105/tpc.107.052100

Tabata, R., Sumida, K., Yoshii, T., Ohyama, K., Shinohara, H., and Matsubayashi, Y. (2014). Perception of root-derived peptides by shoot LRR-RKs mediates systemic N-demand signaling. Science 346, 343-346. doi: 10.1126/science. 1257800

Tao, Y., Ferrer, J. L., Ljung, K., Pojer, F., Hong, F., Long, J. A., et al. (2008). Rapid synthesis of auxin via a new tryptophan-dependent pathway is required for shade avoidance in plants. Cell 133, 164-176. doi: 10.1016/j.cell.2008. 01.049

Tian, H., De Smet, I., and Ding, Z. (2014). Shaping a root system: regulating lateral versus primary root growth. Trends Plant Sci. 19, 426-431. doi: 10.1016/ j.tplants.2014.01.007

Tian, Q., Chen, F., Liu, J., Zhang, F., and Mi, G. (2008). Inhibition of maize root growth by high nitrate supply is correlated with reduced IAA levels in roots. J. Plant Physiol. 165, 942-951. doi: 10.1016/j.jplph.2007.02.011

Tian, Q. Y., Sun, P., and Zhang, W. H. (2009). Ethylene is involved in nitratedependent root growth and branching in Arabidopsis thaliana. New Phytol. 184, 918-931. doi: 10.1111/j.1469-8137.2009.03004.x
Trevisan, S., Manoli, A., and Quaggiotti, S. (2014). NO signaling is a key component of the root growth response to nitrate in Zea mays L. Plant Signal. Behav. 9:e28290. doi: 10.4161/psb.28290

Vidal, E. A., Álvarez, J. M., and Gutiérrez, R. (2014). Nitrate regulation of AFB3 and NAC4 gene expression in Arabidopsis roots depends on NRT1.1 nitrate transport function. Plant Signal. Behav. 9:e28501. doi: 10.4161/psb.28501

Vidal, E. A., Araus, V., Lu, C., Parry, G., Green, P. J., Coruzzi, G. M., et al. (2010). Nitrate-responsive miR393/AFB3 regulatory module controls root system architecture in Arabidopsis thaliana. Proc. Natl. Acad. Sci. U.S.A. 107, 4477-4482. doi: 10.1073/pnas.0909571107

Vidal, E. A., Moyano, T. C., Riveras, E., Contreras-López, O., and Gutiérrez, R. A. (2013). Systems approaches map regulatory networks downstream of the auxin receptor AFB3 in the nitrate response of Arabidopsis thaliana roots. Proc. Natl. Acad. Sci. U.S.A. 110, 12840-12845. doi: 10.1073/pnas.1310937110

Wang, R., Tischner, R., Gutiérrez, R. A., Hoffman, M., Xing, X., Chen, M., et al. (2004). Genomic analysis of the nitrate response using a nitrate reductasenull mutant of Arabidopsis. Plant Physiol. 136, 2512-2522. doi: 10.1104/pp.104. 044610

Won, C., Shen, X., Mashiguchi, K., Zheng, Z., Dai, X., Cheng, Y., et al. (2011). Conversion of tryptophan to indole-3-acetic acid by TRYPTOPHAN AMINOTRANSFERASES OF ARABIDOPSIS and YUCCAs in Arabidopsis. Proc. Natl. Acad. Sci. U.S.A. 108, 18518-18523. doi: 10.1073/pnas.11084 36108

Yan, Y., Wang, H., Hamera, S., Chen, X., and Fang, R. (2014). miR444a has multiple functions in the rice nitrate-signaling pathway. Plant J. 78, 44-55. doi: $10.1111 /$ tpj.12446

Yu, L. H., Miao, Z. Q., Qi, G. F., Wu, J., Cai, X. T., Mao, J. L., et al. (2014). MADS-Box transcription factor AGL21 regulates lateral root development and responds to multiple external and physiological signals. Mol. Plant 7, 1653-1669. doi: 10.1093/mp/ssu088

Yu, P., Baldauf, J., Lithio, A., Marcon, C., Nettleton, D., Li, C., et al. (2016). Root type specific reprogramming of maize pericycle transcriptomes by local high nitrate results in disparate lateral root branching patterns. Plant Physiol. 170, 1783-1798. doi: 10.1104/pp.15.01885

Yu, P., Eggert, K., von Wirén, N., Li, C., and Hochholdinger, F. (2015). Celltype specific gene expression analyses by RNA-Seq reveal local high nitrate triggered lateral root initiation in shoot-borne roots of maize by modulating auxin-related cell cycle-regulation. Plant Physiol. 169, 690-704. doi: 10.1104/ pp.15.00888

Yu, P., Li, X., Yuan, L., and Li, C. (2014). A novel morphological response of maize (Zea mays) adult roots to heterogeneous nitrate supply revealed by a split-root experiment. Physiol. Plant. 150, 133-144. doi: 10.1111/ppl.12075

Zhang, H., and Forde, B. G. (1998). An Arabidopsis MADS box gene that controls nutrient-induced changes in root architecture. Science 279, 407-409. doi: 10.1126/science.279.5349.407

Zhang, H., Jennings, A., Barlow, P. W., and Forde, B. G. (1999). Dual pathways for regulation of root branching by nitrate. Proc. Natl. Acad. Sci. U.S.A. 96, 6529-6534. doi: 10.1073/pnas.96.11.6529

Zhao, Y. (2012). Auxin biosynthesis: a simple two-step pathway converts tryptophan to indole-3-acetic acid in plants. Mol. Plant 5, 334-338. doi: $10.1093 / \mathrm{mp} / \mathrm{ssr} 104$

Conflict of Interest Statement: The authors declare that the research was conducted in the absence of any commercial or financial relationships that could be construed as a potential conflict of interest.

Copyright (c) 2017 Sun, Yu and Hu. This is an open-access article distributed under the terms of the Creative Commons Attribution License (CC BY). The use, distribution or reproduction in other forums is permitted, provided the original author(s) or licensor are credited and that the original publication in this journal is cited, in accordance with accepted academic practice. No use, distribution or reproduction is permitted which does not comply with these terms. 